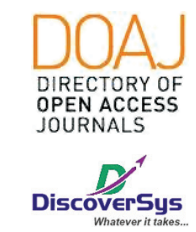

Published by DiscoverSys

\section{Proporsi depresi pada penderita diabetes melitus tipe 2 di RSUP Sanglah Denpasar}

\author{
Gede Aditya Ersa Krisnawan, ${ }^{1 *}$ Putu Aryani, ${ }^{2}$ Komang Ayu Kartika Sari ${ }^{2}$
}

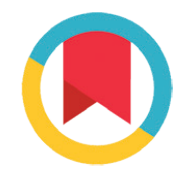

CrossMark

\title{
ABSTRACT
}

Introduction: Over 285 millions of people in 2010 in the world live with diabetes mellitus type 2 (DMT2). In Indonesia based on Riskesdas 2013, 2.45 millions of people live with DMT2 or around $1.5 \%$ of Indonesia's total population. One of the disease causded by DMT2 is depression. 30\% people with DMT2 has also experience depression. Depression in Indonesia based on Riskesdas 2013 has 19 millions of people suffering from it or $11.6 \%$ of Indonesia's total population.

Method: This research was a descriptive study with cross-sectional approach. The subjects was 51 patients diagnosed with diabetes melitus type 2 and did the follow-up in Diabetic Centre of RSUP Sanglah from October-November 2017.Data for this research was acquired from interview using Zung Self Depression Scale (ZSDS).

Result: The results showed $78.9 \%$ sample which experience depression higher in women $(80.0 \%)$, the unemployeed subject (88.6\%), medium educational degree $(86.2 \%)$, duration of illness $>5$ years $(87.5 \%)$, the usage of insulin (81.0\%), and patient with complication history (78.8\%). Conclusion: Higher depression was found in patients with DMT2 with female gender, not working, disease duration $>5$ years, history of insulin use, and had a history of complications. The proportion of depression in DMT2 patient was high, thus further research on relation between depression and DMT2 is necessary to conduct
1Program Studi Pendidikan Dokter, Fakultas Kedokteran Universitas Udayana

${ }^{2}$ Departemen Kesehatan Masyarakat dan Kedokteran Pencegahan (DKMKP) Fakultas Kedokteran Universitas Udayana

${ }^{*}$ Correspondence to: Gede Aditya Ersa Krisnawan, Program Studi Pendidikan Dokter, Fakultas Kedokteran Universitas Udayana 2Departemen adityaersa@gmail.com

Diterima: 10-04-2018 Disetujui: $12-05-2018$ Diterbitkan: 01-08-2019
Keywords: Proportion of depression, diabetes melitus type 2, Zung Self Depression Scale (ZSDS), Diabetic Centre, Denpasar

Cite This Article: Krisnawan, G.A.E., Aryani, P., Sari, K.A.K. 2019. Proporsi depresi pada penderita diabetes melitus tipe 2 di RSUP Sanglah Denpasar. Intisari Sains Medis 10(2): 290-293. D0I: 10.15562/ism.v10i2.246
Latar Belakang: Diabetes melitus tipe 2 (DMT2) di Dunia telah diderita oleh lebih dari 285 juta orang sampai dengan tahun 2010. Berdasarkan Riset Kesehatan Dasar (Riskesdas) 2013, sebanyak 2,45 juta orang mengidap DMT2 atau sekitar 1,5\% dari populasi total penduduk Indonesia. Salah satu penyakit yang bisa terjadi akibat DMT2 adalah depresi. Sejumlah 30\% penderita DMT2 di Dunia mengalami depresi. Depresi di Indonesia sendiri menurut data Riskesdas 2013, ada sekitar 19 juta orang atau 11,6\% jumlah penduduk total. Penelitian ini bertujuan untuk mengetahui proporsi depresi pada penderita penyakit DMT2 di Diabetic Centre RSUP Sanglah.

Metode: Penelitian ini merupakan penelitian deskriptif cross sectional. Subjek penelitian adalah 51 pasien yang terdiagnosis dengan DMT2 dan melakukan pemeriksaan kesehatan kembali di Diabetic Centre RSUP Sanglah pada Bulan Oktober - November 2017.
Data penelitian diperoleh dari wawancara menggunakan kuesioner Zung Self Depression Scale (ZSDS).

Hasil: Penelitian menunjukkan, 78,9\% penderita DMT2 mengalami depresi dimana kejadian depresi lebih tinggi ditemukan pada perempuan $(80,0 \%)$, kelompok subyek yang tidak bekerja $(88,6 \%)$, tingkat pendidikan sedang $(86,2 \%)$, durasi penyakit $>5$ tahun $(87,5 \%)$, penggunaan insulin $(81,0 \%)$, dan pasien dengan riwayat komplikasi (78,8\%).

Simpulan: Depresi lebih tinggi ditemukan pada pasien DMT2 dengan jenis kelamin perempuan, tidak bekerja, durasi penyakit $>5$ tahun, riwayat penggunaan insulin, dan memiliki riwayat komplikasi. Proporsi depresi pada penderita DMT2 ditemukan tinggi, maka dari itu penelitian lebih mendalam tentang hubungan depresi dan DMT2 diperlukan.

Kata Kunci: Proporsi depresi, diabetes melitus tipe 2, Zung Self Depression Scale (ZSDS), Diabetic Centre, Denpasar

Cite Pasal Ini: Krisnawan, G.A.E., Aryani, P., Sari, K.A.K. 2019. Proporsi depresi pada penderita diabetes melitus tipe 2 di RSUP Sanglah Denpasar. Intisari Sains Medis 10(2): 290-293. D0I: 10.15562/ism.v10i2.246

\section{PENDAHULUAN}

Terdapat lebih dari 285 juta penduduk di Dunia menderita diabetes melitus tipe 2 (DMT2) sampai dengan tahun 2010. Diperkirakan dari tahun 2010 hingga 2030, insiden penderita DMT2 akan meningkat sebesar $69 \%$ dan $20 \%$ masing masing bagi Negara berkembang dan Negara maju. ${ }^{1}$ Berdasarkan Riskesdas 2013, sebanyak 2,45 juta orang mengidap DMT2 atau sekitar 1,5\% dari 
populasi total penduduk Indonesia. Sedangkan dilaporkan proporsi DMT2 di Bali dalam kisaran $1,3 \%$ dan cenderung meningkat tiap tahunnya. ${ }^{2}$

DMT2 juga dapat menjadi sebuah faktor risiko terjadinya penyakit mengingat DMT2 merupakan penyakit kronis. Salah satu penyakit yang bisa terjadi akibat DMT2 adalah depresi. Sejumlah 30\% penderita DMT2 di Dunia mengalami depresi, dan berdasakan studi dinyatakan bahwa diabetes melitus meningkatkan angka depresi sebesar 2 kali. ${ }^{3,4}$ Depresi juga meningkatkan tingkat keparahan DMT2, yang menyebabkan semakin turunnya kontrol gula darah, dan semakin buruknya gaya hidup orang tersebut.

Negara-negara seperti Nepal, Pakistan, China, Lithuania, Mexico, dan beberapa negara lainnya sudah melakukan studi tentang proporsi depresi pada penderita DMT2. Dengan menggunakan beberapa metode penilaian terhadap depresi seperti Zung Self Depression Scale (ZSDS), Beck's Depression Inventory (BDI) dan juga Centre for Epidemiological Studies Depression (CES-D), diketahui bahwa orang dengan DMT2, berusia tua, menderita DMT2 dalam waktu lama, memiliki komplikasi, dan BMI dan lingkar pinggang yang besar memiliki proporsi depresi yang besar. ${ }^{1,5-10,14,15}$ Di Indonesia sendiri studi tentang proporsi depresi pada orang dewasa dengan DMT2 masih sangat terbatas jumlahnya, bahkan di Bali belum pernah dilakukan penelitian. Maka

Tabel 1 Distribusi sosiodemografi dan klinis penderita DMT2

\begin{tabular}{|c|c|c|}
\hline & Jumlah ( $\mathrm{N}=51)$ & Persentase (\%) \\
\hline \multicolumn{3}{|l|}{ Jenis Kelamin } \\
\hline Lelaki & 36 & 70,6 \\
\hline Perempuan & 15 & 29,4 \\
\hline \multicolumn{3}{|l|}{ Pekerjaan } \\
\hline Tidak bekerja & 35 & 68,6 \\
\hline Bekerja & 16 & 31,4 \\
\hline \multicolumn{3}{|l|}{ Pendidikan } \\
\hline Rendah & 6 & 11,8 \\
\hline Sedang & 29 & 56,9 \\
\hline Tinggi & 16 & 31,4 \\
\hline \multicolumn{3}{|l|}{ Durasi Penyakit } \\
\hline$<5$ tahun & 19 & 37,3 \\
\hline$>5$ tahun & 32 & 62,7 \\
\hline \multicolumn{3}{|c|}{ Riwayat Pengobatan } \\
\hline Obat oral & 9 & 17,6 \\
\hline Insulin & 41 & 82,4 \\
\hline \multicolumn{3}{|c|}{ Riwayat Komplikasi } \\
\hline Ya & 33 & 64,7 \\
\hline Tidak & 18 & 35,3 \\
\hline
\end{tabular}

dari itu, penelitian ini dilakukan untuk mengetahui kejadian depresi pada pasien DM Tipe 2 yang melakukan pemeriksaan kembali ke Diabetic Centre RSUP Sanglah

\section{BAHAN DAN METODE}

Penelitian ini merupakan penelitian deskriptif cross-sectional. Populasi terjangkau dari penelitian ini adalah penderita DMT2 yang melakukan pemeriksaan kesehatan kembali di Diabetic Centre RSUP Sanglah pada Bulan Oktober hingga November tahun 2017. Adapun kriteria inklusi subjek penelitian ini adalah penderita DMT2 yang datang untuk pemeriksaan kesehatan kembali di Diabetic Centre RSUP Sanglah tahun 2017 dan bersedia berpartisipasi dalam penelitian ini (menandatangani lembar persetujuan/ informed consent). Kriteria eksklusi pada subyek penelitian adalah pasien yang memiliki kondisi medis yang lemah sehingga tidak memungkinkan untuk diwawancara.

Subyek dalam penelitian ini dipilih menggunakan teknik consecutive sampling, dimana semua penderita DMT2 yang melakukan pemeriksaan kesehatan kembali di Diabetic Centre RSUP Sanglah yang memenuhi kriteria inklusi dan eksklusi ditawarkan untuk berpartisipasi dalam penelitian. Data diperoleh melalui wawancara dengan menggunakan pedoman kuesioner depresi yang diadaptasi dari Zung Self Depression Scale (ZSDS). Data hasil penelitian ini dianalisis secara univariat untuk mencari distribusi frekuensi masing masing variabel, dan dianalisis secara bivariat untuk melihat distribusi depresi berdasarkan karakteristik sosiodemografi dan riwayat klinis penderita. Penelitian ini telah mendapatkan persetujuan dari komisi etik FK Unud dengan Surat Keterangan Laik Etik No. 1972/UN.14.2/KEP/2017 tanggal 22 September 2017.

\section{HASIL}

Hasil penelitian menunjukkan bahwa rerata usia sampel adalah 59,8 tahun dengan jumlah lebih banyak ditemukan pada lelaki $(70,6 \%)$, tidak bekerja $(68,6 \%)$, tingkat pendidikan sedang $(55,8 \%)$, durasi penyakit lebih dari 5 tahun $(61,5 \%)$, riwayat pengobatan dengan insulin (82,4\%), dan riwayat komplikasi (64,7\%). Tabel 2. menunjukkan kejadian depresi penderita DMT2 adalah sebesar $78,4 \%$. Tabel 3. menggambarkan kejadian depresi lebih tinggi pada penderita DMT2 berjenis kelamin perempuan ( $80 \%)$, sampel yang tidak bekerja $(88,6 \%)$, tingkat pendidikan sedang $(86,2 \%)$, durasi penyakit $>5$ tahun $(87,5 \%)$, menggunakan insulin $(81,0 \%)$, dan memiliki riwayat komplikasi $(78,8 \%)$. 
Tabel 2 Proporsi depresi penderita DMT 2

\begin{tabular}{lcc}
\hline Status Depresi & Frekuensi $(\mathbf{N}=\mathbf{5 1})$ & Persentase $(\%)$ \\
\hline Depresi & 40 & 78,4 \\
Tidak Depresi & 11 & 21,6 \\
Total & 51 & 100 \\
\hline
\end{tabular}

Tabel 3 Proporsi kejadian depresi berdasarkan sosiodemografi dan klinis penderita DMT2

\begin{tabular}{|c|c|c|c|}
\hline Variabel & $\begin{array}{c}\text { Depresi } \\
\text { n (\%) }\end{array}$ & $\begin{array}{c}\text { Tidak Depresi } \\
\text { n (\%) } \\
\end{array}$ & $\begin{array}{c}\text { Total } \\
\mathbf{n}\end{array}$ \\
\hline \multicolumn{4}{|l|}{ Jenis Kelamin } \\
\hline Lelaki & $28(77,8)$ & $8(22,0)$ & 36 \\
\hline Perempuan & $12(80,0)$ & $3(20,0)$ & 15 \\
\hline \multicolumn{4}{|l|}{ Pekerjaan } \\
\hline Tidak bekerja & $31(88,6)$ & $4(11,4)$ & 35 \\
\hline Bekerja & $9(56,3)$ & $7(43,7)$ & 16 \\
\hline \multicolumn{4}{|l|}{ Pendidikan } \\
\hline Rendah & $4(82,4)$ & $2(17,6)$ & 6 \\
\hline Sedang & $25(86,2)$ & $4(13,8)$ & 29 \\
\hline Tinggi & $11(68,7)$ & $5(31,3)$ & 16 \\
\hline \multicolumn{4}{|l|}{ Durasi Penyakit } \\
\hline$<5$ tahun & $12(63,2)$ & $7(36,8)$ & 19 \\
\hline$>5$ tahun & $28(87,5)$ & $4(12,5)$ & 32 \\
\hline \multicolumn{4}{|c|}{ Riwayat Pengobatan } \\
\hline Obat oral & $6(66,7)$ & $3(33,3)$ & 9 \\
\hline Insulin & $34(81,0)$ & $8(19,0)$ & 41 \\
\hline \multicolumn{4}{|c|}{ Riwayat Komplikasi } \\
\hline Ya & $26(78,8)$ & $7(21,2)$ & 33 \\
\hline Tidak & $14(77,8)$ & $4(22,2)$ & 18 \\
\hline
\end{tabular}

\section{PEMBAHASAN}

Berdasarkan hasil penelitian didapatkan bahwa 78,4\% penderita DMT2 di Diabetic Centre RSUP Sanglah mengalami depresi, hal serupa ditemukan pada penelitian di Pakistan dan Mexico yang sebagian besar sampel penelitiannya mengalami depresi, namun hasil berbeda ditemukan pada penelitian di China, Palestina, Lithuania, dan Nepal yang sebagian besar sampelnya tidak mengalami depresi. ${ }^{1,5-9}$ Hal ini bisa saja disebabkan karena penelitian ini dilakukan di rumah sakit rujukan yang mayoritas sampelnya memiliki komplikasi. Dari segi usia, rata rata usia sampel penelitian ini berusia 59,82 \pm 7,63 tahun, didapatkan rentangan yang sama pula pada penelitian di China dan Lithuania pada rentangan usia di atas 55 tahun hingga 65 tahun, namun hasil berbeda ditemukan pada penelitian di Thailand yang justru mendapatkan rentang usia lebih banyak pada usia 36-60 tahun. ${ }^{7,910}$ Dari hasil penelitian, sampel perempuan dengan DMT2 mengalami depresi lebih tinggi dibandingkan lelaki, yang pada penelitian di Palestina, China, dan Pakistan mendapatkan hasil yang sama dengan proporsi depresi pada perempuan lebih tinggi secara signifikan. Hal ini disebabkan karena wanita memiliki peranan gender yang lebih spesifik sehingga meningkatkan paparan terhadap pengaruh kontrol emosi dan hormonal yang memicu terjadinya depresi. ${ }^{1,6,9,13}$ Sampel tidak bekerja memiliki proporsi depresi lebih tinggi dibandingkan sampel yang bekerja dengan $88,6 \%$ berbanding $56,3 \%$, hasil ini juga ditemukan pada penelitian di China yang menyebutkan bahwa kehidupan yang tidak produktif dan monoton akan menyebabkan kebosanan dan mempengaruhi emosi sehingga mencetuskan kejadian depresi.,11 Tingkat pendidikan sedang memiliki proporsi depresi tertinggi jika dibandingkan dengan tingkat pendidikan tinggi dan rendah yang hasil ini ditemukan juga pada penelitian di Nepal dan Palestina. ${ }^{1,5}$ Durasi penyakit $>5$ tahun memiliki proporsi depresi dengan persentase lebih tinggi dari durasi $<5$ tahun yang pada penelitian ini, persentasenya sebesar $87,5 \%$ berbanding $63,2 \%$. Hasil yang sama didapatkan dari penelitian di Pakistan dan Lithuania yang menyatakan durasi penyakit secara umum menurunkan kualitas hidup pasien dikarenakan menyebabkan keterbatasan dalam keseharian dan permasalahan emosi serta mental. ${ }^{1,711}$

Secara keseluruhan, di Diabetic Centre RSUP Sanglah ditemukan lebih banyak pasien dengan riwayat komplikasi, hal ini juga ditemukan pada penelitian di Nepal dan Lithuania yang menemukan bahwa terdapat lebih banyak sampel dengan komplikasi pada penelitiannya. .,5-7,9 $^{\text {Sejumlah }}$ $78,8 \%$ pasien dengan komplikasi mengalami depresi, hasil ini juga ditemukan pada penelitian di Lithuania dan Pakistan yang menemukan pasien dengan komplikasi lebih banyak yang mengalami depresi. ${ }^{1,7,12}$

Berdasarkan hasil penelitian didapatkan jumlah pengguna insulin sebagai obat anti diabetes memiliki jumlah lebih banyak dibanding obat oral $(82,4 \%$ berbanding 17,6\%). Dari pengguna insulin tersebut sebanyak $81,0 \%$ sampel mengalami depresi. Hasil ini berbeda dengan temuan studi di Lithuania dan Palestina yang menemukan dari total pengguna insulin lebih banyak tidak mengalami depresi dikarenakan tidak terdapat asosiasi antara penggunaan insulin dengan kejadian depresi. ${ }^{6,7,12}$

\section{SIMPULAN}

Depresi lebih tinggi ditemukan pada pasien DMT2 dengan jenis kelamin perempuan, tidak bekerja, durasi penyakit $>5$ tahun, riwayat penggunaan insulin, dan memiliki riwayat komplikasi. 


\section{DAFTAR PUSTAKA}

1. Khuwaja AK, Lalani S, Dhanani R, et al. Anxiety and depression among outpatiens with type 2 diabetes: a multi-centre study of prevalence and associated factors. BioMed Central Ltd. Diabetes Metabolic Syndrome; 2010;2(1):72

2. Badan Penelitian dan Pengembangan Kesehatan RI. Riset Kesehatan Dasar 2013. Jakarta; Departemen Kesehatan. 2013

3. Kulzer B. Diabetes and depression. Der Diabetol. 2008;4(2):129-42

4. Anderson RJ, Freedland KE, Clouse RE, Lustman PJ. The prevalence of comorbid depression. Diabetes Care; 2001;24(6):234-39.

5. Niraula K, Kohrt B, Flora MS, et al. Prevalence of depression and associated risk factors among persons with type 2 diabetes mellitus without prior psychiatric history: a cross sectional study in clinical settings in urban Nepal. BMC Psychiatry. BMC Psychiatry; 2013;13(1):309

6. Sweileh WM, Abu Hadeed HM, Al Jabi SW, H Zyoud S. Prevalence of depression among people with type 2 diabetes mellitus: a cross sectional study in palestine. BMC Public Health. BMC Public Health; 2014;14(1):163

7. Mikaliukstiene A, Zagminas $\mathrm{K}$, Jouzulynas A, Narkauskaite L, Salyga J, Jankauskiene K, Stukas R, Surkiene G. Prevalence and determinants of anxiety and depression symptoms in patients with type 2 diabetes in Lithuania. Med Sci Monit. 2014;20:182-90

8. Kendzor DE, Chen M, Reininger BM, Businelle MS, Stewart DW, Fisher-Hoch SP, Rentfro AR, Wetter DW, McCormick JB. The association of depression and anxiety with glycemic control among mexicang americans with diabetes living near the U.S.-Mexico border. BMC Public Health. BMC Public Health; 2014;14(1):176
9. Wang L, Song R, Chen Z, Wang J, Ling F. Prevalence of depressive symptoms and factor associated with it in type 2 diabetic patiens: a cross-sectional study in China. BMC Public Health. BMC Public Health; 2015;15(1):4-8

10. Thongsai S, Watanabenjasopa S, Youjaiyen M. Depression in patients with type II diabetes: case study at diabetic outpatent clinic, in Samut Prakan. Global Health Science. 2014;6(1):127-34

11. Andreoulaksi E, Hyphantis T, Kandylis D. Depression in diabetes mellitus: a comprehensive review. Hippokratia. 2012;16(3):205-14

12. Fery F, Paquot N. Etiopathogenesis and pathophysiology of type 2 diabetes. Rev Med Liege. 2010;60(5-6):361-8

13. Nordstrom A, Hadrevi J, Olsson T, et al. Higher prevalence of type 2 diabetes in men than women is associated with difference in visceral fat mass. Endocrinology Metabolic Clinical Journal. 2016;101(10):3740-6.

14. Oraki M, Zarrati N, Zarrati I. Comparison of life expectacy, quality of life, irrational health beliefs, health locus of control and hospital depression in patients undergoing hemodialysis and heart transplant in Shahid-Rajee hospital. Bali Med J. 2018;7(1):177-81.

15. Pertiwi GAR, Aryawangsa AAN, Prabawa IPY, Manuaba IBAP, Bhargah A, Budiana IPG. Factor associated with visit-to-visit variability of blood pressure in hypertensive patients at primary health care service, Tabanan, Bali, Indonesia. FMCH. 2018;6(4):191-199. DOI: https://doi. org/10.15212/FMCH.2018.0124

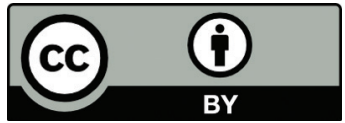

This work is licensed under a Creative Commons Attribution 